\title{
UNDERSTANDING SHORT-TERM RENTAL DATA SOURCES - A VARIETY OF SECOND-BEST SOLUTIONS
}

\author{
Adam Pawlicz \\ Catherine Prentice
}

https://doi.org//10.20867/tosee.06.39

\begin{abstract}
Purpose - This paper aims to identify major supply data sources for short-term rental market research and to provide their advantages and limitations.

Methodology - In the paper a grounded approach was used based on a literature review. This review comprised two steps with the first being the query in major databases that was supplemented by academic search engine that resulted in 170 articles. The second step was to investigate the papers' methodological sections to identify characteristics and limitations of all data sources.

Findings - This study identifies three major data sources for the short-term rental market: web scraping with the use of self-made bots, Inside Airbnb and Airdna. A majority (e.g. 74\% of papers using Airdna as a source) did not mention any limitations and provide no discussion about the data source, while the remainder gave only superfluous information about possible limitations of its use. Their characteristics and limitations are extensively discussed using a proposed framework that consists of three levels: intermediary, web scraping, and source-specific.

Contribution - Very limited number of studies have focused on the short-term rental data sources and this is the first one that discusses advantages and limitation of their use. This paper may be of help to academics or professionals in identifying the right source of data to suit their technical knowledge, financial and technical resources and research areas.
\end{abstract}

Keywords: Airbnb, short-term rental market, web scraping, Airdna, Inside Airbnb.

\section{INTRODUCTION}

A sine qua non of sound research is undoubtedly reliable data, and the hospitality market is no exception. Hospitality supply consists of two main types of accommodation: traditional accommodation, which includes hotels and other establishments, and that supplied by the short-term rental (STR) market, which is predominantly represented by apartments. The former establishments are usually obliged to report their capacity and, in some cases, also occupancy to statistical offices, but the latter are mostly still not part of official statistics. Moreover, the STR market, which in many destinations is of a size estimated to be more than $70 \%$ of the traditional market (Gutiérrez et al. 2017), is very volatile and still partially operates in the grey economy. As a result, a simple question about hospitality supply in a region often cannot be met with a precise response, neither by the destination marketing department, nor by industry players or academia.

As the process of daylighting businesses providing services in the STR market is in many destinations still in its nascent stage, the market size is usually estimated based on the 
ToSEE - Tourism in Southern and Eastern Europe, Vol. 6, pp. 573-585, 2021.

A. Pawlicz, C. Prentice: UNDERSTANDING SHORT-TERM RENTAL DATA SOURCES ...

analysis of sharing economy platforms' (intermediaries) websites, which publicly display the available supply to prospective clients. Unfortunately, for various reasons, neither Airbnb, the major intermediary, nor other sharing economy platforms neither disclose any statistics-like data nor provide any aggregated data, with the exception of a few industry reports. As a result, academics, industry players and government agendas need to use other second-best solutions to assess STR market size. There are three major data sources (web scraping with self-made bots, Inside Airbnb and Airdna), as well as a few others of lesser importance. These vary according to the applied technology, quality, scope, cost, and finally labour involvement. Although there is an abundance of contributions using such STR data sources in both popular and scientific literature, very little attention is given to their limitations. The use of different methods for collecting data may result in biased research findings, misallocation of business resources, and failure in achieving policy goals. Hence, this paper aims to systematize the sources and compare their usage in the literature. Moreover, there are two other unanswered research questions, namely: What are the pros and cons of the usage of various data sources? How can source-specific limitations be addressed?

The paper begins by providing a brief description of the research design and the general limitations of intermediaries' data usage in the STR market. Following this, the major issues related to data collection using web scraping are discussed. Next, the sourcespecific limitations and advantages of the three main STR market data sources are presented. Recommendations and conclusions constitute the last part of this paper.

\section{METHODOLOGY}

To answer the research questions mentioned above, this paper conceptually synthesizes knowledge of STR market data sources, with particular emphasis on their limitations. The process of collecting relevant papers commenced with the identification of key STR market data sources and a search query in major databases. However, the number of query results was moderate as data sources receive little attention in methodology sections and as such are hardly included in papers' keywords. Then, using Dolnicar's (2019) approach, the results were supplemented by a Google Scholar search to ensure the study had a wider academic coverage. Three main queries were conducted to look for three principal data sources: web scraping, Airdna, and Inside Airbnb.

The first results to the query "airdna airbnb" (A query with "airdna" alone produced many results related to medicine, so instead "airdna airbnb" was used) appeared in 2015, but these are either articles that were published later or non-scientific sources. However, using a search engine, the number of search results grows rapidly, with 31 items in 2016, 98 in 2017, 149 in 2018, 211 in 2019 and 183 in 2020 (accessed on October 2, 2020). Then, after a brief analysis of all contributions and removal of both non-English papers and those that use only Airdna as a reference, a collection of papers was obtained with Airdna data that constituted a basis for further calculations. This resulted in a set of 104 contributions with a clear upward trend $(2016-3,2017-3,2018-23,2019-41,2020$ - 34). What is important is that as many as 74 of them (71\%) did not mention any limitations (including information about data cleaning) regarding the Airdna data source. Similar results were obtained for a query with the keywords "Inside Airbnb" (948 
ToSEE - Tourism in Southern and Eastern Europe, Vol. 6, pp. 573-585, 2021.

A. Pawlicz, C. Prentice: UNDERSTANDING SHORT-TERM RENTAL DATA SOURCES ...

results), of which 194 results contained both Inside Airbnb and Airdna. However, the search for Inside Airbnb is much less reliable, as Google Scholar also shows research containing the words "inside" and "Airbnb" even if they are written together. Similar problems appeared with a "web scraping Airbnb" search. Nevertheless, in both cases, the most relevant 100 results were examined. This process yielded an total of 170 articles for subsequent analysis. Apart from peer-reviewed articles, the sample consisted of theses, working papers and reports. An analysis of the theses was especially constructive as they comprise more detailed methodological sections than the latter.

Papers identified through the query are mostly original contributions while only 3 papers deal with various issues of short-term rental data. Agarwal et al. (2019) compared the Airdna and STR data sources with an emphasis on performance metrics provided by those two data providers. Scassa (2019) discussed the legal issues of automatically gathering publicly available data, while Alsudais (2020) pointed out inaccuracies in data regarding reviews provided by InsideAirbnb. In other contributions, discussion regarding data sources is limited to methodology sections. No prior research discussed the general limitations of different short-term rental data sources and addressing this research gap constitutes the main aim of this paper.

As the results consisted of different types of contributions, the use of a standard literature meta-analysis applied in other papers dealing with literature progress in the field of the sharing economy (Guttentag 2019; Dann et al. 2019; Somers et al. 2018; ter Huurne et al. 2017; Cheng 2016) was rejected, and a grounded approach was applied that scrutinized the main conceptual accent of each contribution (Standing et al. 2019; Urquhart 2012). The grounded approach aims to build a theoretical classification from the literature rather than impose a classification structure on it. The substance of each paper was analysed by examining the title, abstract, keywords, stated goals, methodological section and a conceptual review of its full content. On this basis, the major advantages and usage limitations of selected STR market data sources were identified.

\section{GENERAL LIMITATIONS OF INTERMEDIARIES' DATA}

Research data about the STR market may be based on a wide variety of sources. The primary source, as in the case of the traditional hospitality market, is the statistical office. As STR market providers very often rely on intermediaries in their service distribution, middlemen represent another major source of data. This data can either be directly provided by an intermediary, manually retrieved from its website or scraped automatically. The web scraping process may be organized by a research team or obtained from various organizations, which can be either non-profit or operating on a commercial basis. Finally, part of the data that is provided by the latter may be collected manually from their websites. 
ToSEE - Tourism in Southern and Eastern Europe, Vol. 6, pp. 573-585, 2021.

Figure 1: Variety of STR market data sources

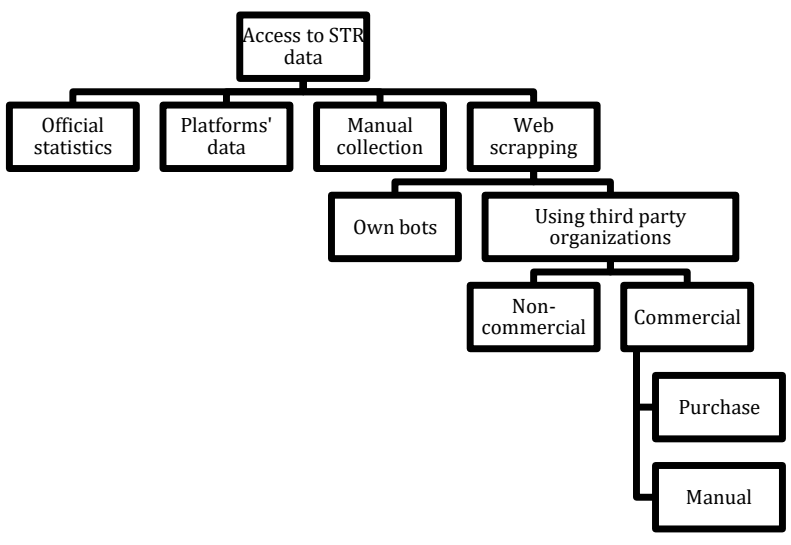

Own

STR market research that draws accommodation data from official sources is a rare exception (Cors-Iglesias et al. 2020). The main limitation of official data, which is at the same time a major advantage of using intermediary data, is the inclusion of illegal rentals in the latter. As a result, official data about capacity and occupancy is usually incomplete and contains little additional performance information. Hence, a common strategy is to obtain data from market intermediaries called sharing economy platforms (Sales-Favà and Módenes 2017), which were responsible for the unprecedented growth of the STR market in the second decade of the $21^{\text {st }}$ century. They operate globally on a market characterized by considerable economics of scale (due to high network effects), where the undisputed leader position belongs to Airbnb. Similarly to other platforms, Airbnb is known for its reluctance to share business data, even in an aggregated form. Exceptions are made only after legal action, and even then data is shared only with public administration and cannot be used in academia (Comp. Abrams 2018). However, even perfectly accurate Airbnb data would only constitute an estimate for the STR market, due to the following characteristics:

1. Use of platforms by traditional hospitality providers. With minuscule fixed costs for maintaining an online distribution channel, not only apartment providers but also traditional hoteliers offer their services through multiple intermediaries. As a result, these numbers may overestimate the real values. This issue can only be addressed by manually removing hotel or other non-apartment listings (Demir and Emekli 2019; Robertson et al. 2020).

2. Direct bookings. A certain proportion of guests, which may represent a substantial market share, book directly.

3. Market volatility. Some rentals are booked very occasionally with highly elevated prices primarily set for times of high demand, while the premises remain constantly available, others are simply withdrawn from the STR market. Some properties fluctuate between STR and long-term markets according to the market stage. Many are rented to students during the academic year, while in the summer or during major events they add to the STR supply (Robertson et al. 2020). 
ToSEE - Tourism in Southern and Eastern Europe, Vol. 6, pp. 573-585, 2021.

A. Pawlicz, C. Prentice: UNDERSTANDING SHORT-TERM RENTAL DATA SOURCES ...

4. Others. Some properties are listed multiple times by different users to increase visibility (Demir and Emekli 2019). Moreover, guest no-shows, last-minute discounts, additional guest fees and extended stays are not always reflected in intermediary availability (Comp. Beghelli 2020; Robertson et al. 2020; Uzunca and Borlenghi 2019; G. Chen et al. 2020).

The problems described in point 3 alone prevent anyone from answering the question posed in the introduction, as hospitality supply, in the era of a well-developed STR market, is not as inelastic as it used to be before the 2010s. As demand rises, more apartments enter the supply, thus moderating price increases. Alternatively, when demand falls during a crisis, apartments are transferred back to the long-term market (Dolnicar and Zare 2020), which results in a less drastic fall of the equilibrium price in comparison to the traditional inelastic market.

\section{MANUAL DATA COLLECTION}

Although there are exceptions (Dinatale et al. 2017), obtaining raw data directly from Airbnb or any other intermediary is exceptional, and usually only possible in the case of research in which intermediaries' employees are involved. This was commonly exploited by researchers, who manually collected data for the first academic papers dealing with the STR market (Comp. Edelman and Luca 2014). The main advantage is the possibility to instantly filter outdated and fake listings and collect information which can almost never be accessed automatically (such as picture characteristics etc.). The cost and simplicity were other advantages of this method, while the obvious drawback is the fact that the outcome is only a snapshot of Airbnb usage effective at one point in time. This may not represent the real supply, as the number of providers, their availability and prices may vary considerably. Finally, manual data collection is an arduous labour-intensive task characterised by inevitable human errors, which has become almost obsolete as commercial web-scraping companies have emerged.

\section{WEB SCRAPING}

\subsection{General limitations of web scraping}

An alternative to manually collecting Airbnb data is the usage of an automated method - web scraping. Without delving into the technical details, web scraping is a process in which a bot (program) continuously visits the intermediary web site and creates a reservation query which must include a given number of travellers, date of arrival and length of stay in a chosen geographical area. The bot then collects output information such as availability and price. Intermediary websites are generally easily accessible as all listings are structured in the same pattern. However, web scraping is certainly not as accurate as intermediary data as its quality will inevitably suffer from additional limitations: 
ToSEE - Tourism in Southern and Eastern Europe, Vol. 6, pp. 573-585, 2021.

A. Pawlicz, C. Prentice: UNDERSTANDING SHORT-TERM RENTAL DATA SOURCES ...

1. Platform interference. Commercial platforms prohibit machine searches of their sites and Airbnb is no exception (Alsudais 2020). Technical issues such as IP detection, fingerprinting, proxy blocks and rate of access control are usually circumvented with the usage of multiple IDs, hiding behind proxy servers, using the Tor network, by reducing the number of search queries (Wegmann and Jiao 2017) or creation of an algorithm developed to simulate how a human would use the website (Longo 2017). As platforms attempt to block automated crawling, the process, which resembles a technological "arms race" between organizations or scholars and Airbnb, is becoming much more uncertain and complex (Comp. Claussen and Peukert 2019).

2. Biased geographical location. To prevent opportunism, Airbnb latitude-longitude coordinates represent only a random point within a $200 \mathrm{~m}$ radius of the listing's actual location rather than the exact location (according to other sources it is $130 \mathrm{~m}$ (Crommelin et al. 2018) or 150m (Ayouba et al. 2020)).

A bot may be constructed by the research team or by an external organization which provides the data. The two most popular STR data providers are the non-profit Inside Airbnb and the commercial Airdna. The main advantage of web scraping in comparison to manual data collection is its accuracy and time saving due to limited labour requirements.

Most of the studies use just one source of data, but sometimes data from non-profit organizations is complemented by that from for-profit bodies (Nieto García et al. 2020; Yrigoy 2019; Amore et al. 2020; Ardura Urquiaga et al. 2020; Griffiths 2017; Crommelin et al. 2018).

\subsection{Self-made bots}

Automated scraping addresses numerous flaws of manual collection as it can be repeated and allows other data from a given geographical area to be obtained. The obvious advantage is the possibility of control over the entire process of data collection (Gyódi 2019). There are, however, several methodological problems associated with STR web scraping:

1. Sampling problem. As mentioned earlier, the STR market is very volatile and one query may produce a biased number of listings. To resolve this issue, on the one hand, the query may be repeated on numerous days before one arrival time (e.g. 90 days before, then 60, 30, 15 and so on until arrival day).

2. Occupancy problem. Since 2015, the Airbnb site does not differentiate between blocked and reserved listings which does not pose a difficulty for tourists, but it prevents web scraping bots from assessing the exact occupancy rate.

3. Need for data cleaning. Similarly to data obtained directly from an intermediary, raw data consists of fake, inactive, duplicated and test listings which normally need to be cleaned before research (Sawatzky 2016; Adamiak 2020). This issue may be resolved by running scrapes several times (Griffiths 2017).

4. One platform data. Web scraping does not allow for the collection and comparison of data from various platforms unless the research team create more bots. Then, however, the issue of duplicate listings arises. 
ToSEE - Tourism in Southern and Eastern Europe, Vol. 6, pp. 573-585, 2021.

A. Pawlicz, C. Prentice: UNDERSTANDING SHORT-TERM RENTAL DATA SOURCES ...

5. Legal issues. Web crawling on Airbnb and other intermediaries' websites requires creating a user to access the data of interest. This is associated with agreeing to terms of service, which, in the case of Airbnb and many other platforms, explicitly prohibit data crawling (Scassa 2019; Scassa 2018; Claussen and Peukert 2019).

\subsection{Open datasets (Inside Airbnb)}

As demand for sharing economy market intelligence is high, numerous organizations have emerged that provide such data. They can be divided into two groups according to their business orientation. The first group consists of non-profit oriented organizations that provide open data pro bono or, as Fierro and Aranburu (2018) put it "democratize Airbnb information", while the latter includes for-profit organizations that are discussed in the next section.

Although the most notable example of an open dataset for the STR market is undoubtedly Inside Airbnb, other local organizations also exist, such as the Spanish Terraferida and Dinsairbnb (Valdivielso and Moranta 2019), or Airbnbvsberlin (Suciu 2018), but these provide very limited und infrequent data. The only alternative to Inside Airbnb that is frequently used in research is the DataHippo project (Comp. Gutiérrez and Domènech 2020), which provides detailed data for Spain, Portugal and Andorra.

Besides the above-mentioned advantages, the use of Inside Airbnb has certain inherent limitations:

1. One platform data. This organization, as the name suggests, only provides information about Airbnb listings.

2. Selected locations. The number of available locations in Inside Airbnb is growing, but it still represents data for only the most developed destinations. This precludes any research that addresses the problem in other areas, e.g. in the developing world (Jones et al. 2019).

3. Random updates. The website provides a new set of data every month for major destinations, but for lesser-known cities data is provided more occasionally. This limits the possibility to perform a longitudinal analysis (Zhao and Rahman 2019).

4. Incorrect reviews. Alsudais (2020), by examining Inside Airbnb data sets for Los Angeles, in the USA, found that $0.15 \%$ of all listings have at least one incorrectly added review, while for the first 500 listings this ratio is as high as $6.2 \%$.

\subsection{Commercial providers (Airdna)}

The other group of data providers are opportunistic businesses that rely on ongoing access to Airbnb and other intermediaries' data. They constantly scrape publicly accessible sharing economy platforms' web sites and later trade the data collected either as raw data sets or by offering analytics services. Despite a few exceptions, the major commercial STR data source for academia is provided by Airdna, probably because it follows a well-known freemium model. While basic information is provided at no cost, more detailed or extended data is sold either as a premium account or as raw data for a 
ToSEE - Tourism in Southern and Eastern Europe, Vol. 6, pp. 573-585, 2021.

A. Pawlicz, C. Prentice: UNDERSTANDING SHORT-TERM RENTAL DATA SOURCES

certain area and period. The basic free information covers the number of active rentals, rental growth, average prices, occupancy and other STR-specific statistics, such as information about sharing economy development, which can be obtained for various cities, counties or even as detailed as zip code areas. The purchased data set contains 45 different characteristics such as unique IDs for property and host, geographic information, price information, etc. (Tong and Gunter 2020). Some studies also use Airdna analytics like regulatory level or market development index (Y. Chen et al. 2020).

For research purposes, data is either collected manually from the Airdna site (Yrigoy 2019; Pawlicz and Vrtodusic Hrgovic 2020; Sandusky et al. 2019), purchased from Airdna as part of a subscription (Jokela and Minoia 2020) or as raw data (the vast majority of sources). Rarely is raw Airdna data is provided for academic purposes without a charge (Mohamad 2016; Joseph and Varghese 2019), but the company claims to offer data for academic purposes at a discounted price (DiNatale et al. 2018).

The advantages of Airdna data centre mostly on addressing the limitations of data obtained by other scraping methods. Grisdale (2019) stresses the continuity (on a daily basis) of the scraping process applied by Airdna as its main advantage. Similar views can be found in other research (Ioannides et al. 2019; Oskam 2019; Sainaghi and Baggio 2020).

The other advantage of Airdna data over that obtained by one's own web scraping is the possibility to obtain an estimation of the occupancy level, as the Airbnb site does not differentiate between listings that are blocked or reserved. Airdna created an automated learning model (similar to Inside Airbnb) to assess occupancy based on a combination of its existing historical dataset of activity and other publicly available data (e.g. ratings and reviews) (Wachsmuth and Weisler 2018; Crommelin et al. 2018; Agarwal et al. 2019; Schäfer and Tran 2020; Robertson et al. 2020). According to Oskam (2020), the reservation status is extrapolated using the historical behaviour of the property.

Airdna first provided information based on Airbnb data, although this was later extended to Homeaway (now VRBO). These listings were only added retroactively back to 2017. As a result, the Airdna data shows a trend break in early 2017 (Sandusky et al. 2019). As other sharing economy platforms are not included in Airdna, this leads to the assumption that real STR numbers are systematically underestimated, but there is no research addressing this issue.

The major limitations of Airdna data are as follows:

1. Data collection. The methodology, for competitive reasons, is revealed neither to the public nor to academia. Some researchers report vague answers from Airdna when inquiring about their methodology (Tenezakis 2019; Agarwal et al. 2019), while others appreciate company collaboration (Sainaghi and Baggio 2020). As mentioned before, web scraping is not permitted by the terms of service of Airbnb, however, as Airdna has been continuously able to obtain Airbnb information since 2014, this led Scassa (2018) to speculate on the existence of a non-public agreement between the organizations. 
ToSEE - Tourism in Southern and Eastern Europe, Vol. 6, pp. 573-585, 2021.

A. Pawlicz, C. Prentice: UNDERSTANDING SHORT-TERM RENTAL DATA SOURCES ...

2. Analytics calculation. An extensive discussion about biases in Airdna data has been conducted based on the Virginia Beach, USA case study (Agarwal et al. 2019). The authors found numerous inaccuracies (including only "booked listings" in the calculation of occupancy etc., inconsistencies with counting the number of available room nights in one- or multi-bedroom properties), and in general concluded that Airdna results are biased upward regarding ADR, occupancy and RevPAR.

3. Commercial provider. It is not ideal to rely on data provided by a company with a vested interest in selling data to investors (Robertson et al. 2020), especially one that openly goes on the defence in debates about the interpretation of Airbnb data (Hoffman and Heisler 2020).

4. Data cleaning. Airdna data also contains fake and test listings that need to be eliminated before calculations (Dinatale et al. 2017; Nyborg and Pedersen 2020; Rubino et al. 2020; L. Chen et al. 2020). In some research, this can be as much as 16\% (Rubino and Coscia 2019) or even 74\% (L. Chen et al. 2020).

The above-mentioned three major STR data sources (own web scraping, Inside Airbnb and Airdna) cannot be directly compared as each of them has their advantages and limitations. While Jiao and Bai (2020) consider web scraping to be the most effective, others regard Airdna as the best available source for research into the Airbnb market (Kwok and Xie 2019; Oskam 2019; Magaš and Zadel 2020; Schäfer and Tran 2020). Similarly, Grisdale (2019) claims that for this reason, Airdna data is more accurate than that developed by Murray Cox (the founder of Inside Airbnb) and Tom Slee (who published a publicly available script for Airbnb web scraping). In the same vein, (H. S. Chen et al. 2020) found that the number of listings that were continuously available from Airdna was about twice as many as from Inside Airbnb datasets based on single scrapes. Although Airdna provides information from two sharing economy platforms, some authors openly underline that working with raw data provided directly by Airbnb would be preferable (Tuatagaloa and Osborne 2018; Wachsmuth and Weisler 2018; Schäfer and Tran 2020). While discussing the limitations of the three major data sources described above, one needs to bear in mind that they all suffer from general limitations regarding intermediaries' data and web scraping.

On the traditional hospitality market, official statistics are complemented by hotel consulting agencies that provide information about revenue, profitability etc. (although this is limited to major destinations). In contrast, STR market statistics are almost entirely dependent on data scraped from intermediaries' web sites. It is improbable that without daylighting of the STR market, the public will be able to obtain official statistics at the very least on its capacity and occupancy.

\section{CONCLUSIONS, LIMITATIONS AND FURTHER RESEARCH}

While conducting research in STR market, a wide variety of different data sources is used. Most popular sources rely on the data which is web scrapped from the main STR market intermediary - Airbnb. The main sources used in research are Airdna commercial provider that sells both raw data and analytics for supply, prices and occupancy, InsideAirbnb - non-profit provider of raw data and analytics that include also reviews while the third source is a web scraping conducted by academics 
ToSEE - Tourism in Southern and Eastern Europe, Vol. 6, pp. 573-585, 2021.

A. Pawlicz, C. Prentice: UNDERSTANDING SHORT-TERM RENTAL DATA SOURCES ...

themselves. The use of all three sources is associated with acceptance of both webscraping-related limitations and biases related to use of intermediary data. Additionally, each of those sources has its own limitations which are all discussed in the sections above. The use of them is determined by their availability to the research area, the costs that academics are ready to accept, time they have, the type of data that is needed, availability of technical knowledge that is required to scrap the intermediary website. A clear trade-off is seen between data accuracy, its cost, and time and knowledge of academics. Besides numerous limitations, the majority of survived sources did not mention any source-specific biases in their articles' limitations section.

The main limitations of this study are the following. As search queries in databases with indexed journals produced only a few records, the Google Scholar search engine was used to determine the contributions to be examined. As a result, besides articles in leading journals, contributions from lesser-known journals, theses and reports were also included. Due to the fact that evaluation of the contributions was performed manually, there is naturally the possibility that omissions, human error and subjectivity might occur. Finally, only contributions written in English were considered.

Further research should address issues so far neglected within STR research: the relationship between the presence of STR providers among intermediaries and the type of tourism region; and the methodology for assessing the STR market in non-urban areas, where web scraping should balance the minimum length of stay, and where intermediaries account for much less of the STR market.

\section{REFERENCES}

Abrams, A. (2018), Airbnb Will Start Sharing Guest Data With China Authorities [Online] Available at: https://time.com/5221666/airbnb-china-share-data-chinese-government/ [Accessed: 23 September 2020].

Adamiak, C. (2020), "Peer-to-peer accommodation in destination life cycle: the case of Nordic countries", Scandinavian Journal of Hospitality and Tourism, Vol. 20, No. 3, pp. 212-226.

Agarwal, V., Koch, J.V. and McNab, R.M. (2019), "Differing Views of Lodging Reality: Airdna, STR, and Airbnb", Cornell Hospitality Quarterly, Vol. 60, No. 3, pp. 193-199.

Alsudais, A. (2020), Incorrect Data in the Widely Used Inside Airbnb Dataset. (July).

Amore, A., de Bernardi, C. and Arvanitis, P. (2020), "The impacts of Airbnb in Athens, Lisbon and Milan: a rent gap theory perspective", Current Issues in Tourism.

Ardura Urquiaga, A., Lorente-Riverola, I. and Ruiz Sanchez, J. (2020), "Platform-mediated short-term rentals and gentrification in Madrid", Urban Studies, Vol. 57, No. 15, pp. 3095-3115. https://doi.org/10.1177/0042098020918154

Ayouba, K., Breuillé, M.L., Grivault, C. and Le Gallo, J. (2020). "Does Airbnb Disrupt the Private Rental Market? An Empirical Analysis for French Cities", International Regional Science Review, Vol. 43 No. 1-2, pp. 76-104. https://doi.org/10.1177/0160017618821428

Beghelli, M. (2020), "The Relationship between Airbnb, the Accommodation Industry and New Tourist Flows. The Case of Bologna Metropolitan Area (Italy)", Almatourism - Journal of Tourism, Culture and Territorial Development Vol. 11, No. 21, pp. 79-107.

Chen, G., Cheng, M., Edwards, D. and Xu, L. (2020), "COVID-19 pandemic exposes the vulnerability of the sharing economy".

Chen, H.S., Chen, Y. and He, Y. (2020), "Does terrorism impact on the peer-to-peer accommodation market? Empirical evidence from Airbnb in Paris", Current Issues in Tourism, Vol. 24, No. 13, pp. 17811791. https://doi.org/10.1080/13683500.2020.1784105

Chen, L., Chen, T. L. and Liu, H.K. (2020), "Identifying Airbnb entrepreneurs' roles and competencies: Perspectives from Practitioners", International Journal of Organizational Innovation, Vol. 13, No. 
ToSEE - Tourism in Southern and Eastern Europe, Vol. 6, pp. 573-585, 2021.

A. Pawlicz, C. Prentice: UNDERSTANDING SHORT-TERM RENTAL DATA SOURCES ...

1, pp. $120-135$.

Chen, Y., Huang, Y. and Tan, C.H. (2020), "Short-term rental and its regulations on the home-sharing platform", Information \& Management, Vol. 58, No. 3. pp. 103322. https://doi.org/10.1016/j.im.2020.103322

Cheng, M. (2016), "Sharing economy: A review and agenda for future research", International Journal of Hospitality Management Vol. 57, pp. 60-70. https://doi.org/10.1016/j.ijhm.2016.06.003

Claussen, J. and Peukert, C. (2019), Obtaining Data from the Internet: A Guide to Data Crawling in Management Research. SSRN Electronic Journal.

Cors-Iglesias, M., Gómez-Martín, M.B. and Armesto-López, X.A. (2020), "Peer-to-Peer Accommodation in Rural Areas of Catalonia: Defining Typologies of Rural Municipalities", Sustainability, Vol. 12, No. 15, 6145. https://doi.org/10.3390/su12156145

Crommelin, L., Troy, L., Martin, C. and Parkinson, S. (2018), Technological disruption in private housing markets: The case of Airbnb. Australian Housing and Urban Research Institute.

Dann, D., Teubner, T. and Weinhardt, C. (2019), "Poster child and guinea pig - insights from a structured literature review on Airbnb", International Journal of Contemporary Hospitality Management Vol. 31, No. 1, pp. 427-473. https://doi.org/10.1108/IJCHM-03-2018-0186

Demir, E. and Emekli, G. (2019), "Geographical Distribution of Modern and Postmodern Accommodation Supply: A Case Study of Izmir (Turkey)", Ege Coğrafya Dergisi, Vol. 28, No. 1, pp. 33-50.

Dinatale, S. et al. 2017. Assessing and Responding to Short-Term Rentals in Oregon. Enabling the Benefits of the Sharing Economy.

DiNatale, S., Lewis, R. and Parker, R. (2018), "Short-term rentals in small cities in Oregon: Impacts and regulations", Land Use Policy, Vol. 79, pp. 407-423. https://doi.org/10.1016/j.landusepol.2018.08.023

Dolnicar, S. (2019). "A review of research into paid online peer-to-peer accommodation: Launching the Annals of Tourism Research curated collection on peer-to-peer accommodation", Annals of Tourism Research, Vol. 75, pp. 248-264. https://doi.org/10.1016/j.annals.2019.02.003

Dolnicar, S. and Zare, S. (2020), "COVID19 and Airbnb - Disrupting the Disruptor", Annals of Tourism Research Vol. 83, 102961. doi: 10.1016/j.annals.2020.102961

Edelman, B. and Luca, M. (2014), "Digital discrimination: The case of airbnb. com", Harvard Business School NOM Unit Working Paper 14-054, pp. 1-21.

Fierro, A. and Aranburu, I. (2018), "Airbnb branding: Heritage as a branding element in the sharing economy", Sustainability (Switzerland) Vol. 11, No. 1, 74

Griffiths, S. (2017), Where Home Meets Hotel: Regulating tourist accommodations in the age of Airbnb, Siman Fraser University.

Grisdale, S.E. (2019), Displacement by Disruption: Platform Capitalism, Short-Term Rentals and Urban Transformation in Toronto. Urban Geography.

Gutiérrez, A. and Domènech, A. (2020), "Understanding the spatiality of short-term rentals in Spain: Airbnb and the intensification of the commodification of housing", Geografisk Tidsskrift - Danish Journal of Geography, Vol. 120, No. 2, pp. 98-113. https://doi.org/10.1080/00167223.2020.1769492

Gutiérrez, J., García-Palomares, J.C., Romanillos, G. and Salas-Olmedo, M.H. (2017), The eruption of Airbnb in tourist cities: Comparing spatial patterns of hotels and peer-to-peer accommodation in Barcelona. Tourism Management, Vol. 62, pp. 278-291. https://doi.org/10.1016/j.tourman.2017.05.003

Guttentag, D. (2019), "Progress on Airbnb: a literature review", Journal of Hospitality and Tourism Technology, Vol. 10, No. 4, pp. 814-844. https://doi.org/10.1108/JHTT-08-2018-0075

Gyódi, K. (2019), "Airbnb in European cities: Business as usual or true sharing economy?", Journal of Cleaner Production Vol. 221, pp. 536-551.

Hoffman, L.M. and Heisler, B.S. (2020), Airbnb, Short-Term Rentals and the Future of Housing, Routledge.

ter Huurne, M., Ronteltap, A., Corten, R. and Buskens, V. (2017), "Antecedents of trust in the sharing economy: A systematic review", Journal of Consumer Behaviour, Vol. 16, No. 6, pp. 485-498 https://doi.org/10.1002/cb.1667

Ioannides, D., Röslmaier, M. and Van Der Zee, E. (2019), "Airbnb as an instigator of 'tourism bubble' expansion in Utrecht's Lombok neighbourhood", Tourism Geographies Vol. 21, No. 5, pp. 822840. https://doi.org/10.1080/14616688.2018.1454505

Jiao, J. and Bai, S. (2020), "An empirical analysis of Airbnb listings in forty American cities", Cities, Vol. 99 102618. https://doi.org/10.1016/j.cities.2020.102618

Jokela, S. and Minoia, P. (2020), "Nordic home-sharing utopia: a critical analysis of Airbnb in Helsinki", Scandinavian Journal of Hospitality and Tourism, Vol. 20, No. 3, pp. 227-245. https://doi.org/10.1080/15022250.2020.1774412

Jones, V.C., Kennedy, R.D., Welding, K., Gielen, A.C. and Frattaroli, S. (2019), "The prevalence of fire and $\mathrm{CO}$ safety amenities in Airbnb venues that permit smoking - Findings from 17 countries", Preventive Medicine, Vol. 123, pp. 8-11. https://doi.org/10.1016/j.ypmed.2019.02.021

Joseph, G. and Varghese, V. (2019), "Analyzing Airbnb customer experience feedback using text mining", in 
ToSEE - Tourism in Southern and Eastern Europe, Vol. 6, pp. 573-585, 2021.

A. Pawlicz, C. Prentice: UNDERSTANDING SHORT-TERM RENTAL DATA SOURCES ...

Big Data and Innovation in Tourism, Travel, and Hospitality: Managerial Approaches, Techniques, and Applications, Springer Singapore, pp. 147-162.

Kwok, L. and Xie, K.L. (2019), "Pricing strategies on Airbnb: Are multi-unit hosts revenue pros?", International Journal of Hospitality Management, Vol. 82, pp. 252-259. https://doi.org/10.1016/j.ijhm.2018.09.013

Longo, R.S.P. (2017), Tourism and Real Estate Markets, Nova School of Business and Economics.

Magaš, D. and Zadel, Z. (2020), "Influence of Airbnb on hotel sector performance indicators in Croatia", in Tourism \& Hospitality Industry 2020, Congress Proceedings, pp. 147-161.

Mohamad, H. (2016), Estimating the Impact of Airbnb on Hotels in Toronto, Massachusetts Institute of Technology.

Nieto García, M., Muñoz-Gallego, P.A., Viglia, G. and Gonzalez-Benito, O. (2020), "Be Social! The Impact of Self-Presentation on Peer-to-Peer Accommodation Revenue", Journal of Travel Research, Vol. 59, No. 7, pp. 1268-1281. https://doi.org/10.1177/0047287519878520

Nyborg, Ø. and Pedersen, C. (2020), The Effect of Airbnb on Real Estate Prices A Panel Data Regression Study on Variables Affecting Real Estate Prices, The Arctic University of Norway.

Oskam, J. (2019), The Future of Airbnb and the "Sharing Economy": The Collaborative Consumption of our Cities, Channel ViewPublications, Bristol.

Oskam, J. (2020), "Eiffel Tower and Big Ben, or 'off the beaten track'? Centripetal demand in Airbnb", Hospitality \& Society, Vol 10, No. 2, pp. 127-155. https://doi.org/10.1386/hosp_00017_1

Pawlicz, A. and Vrtodusic Hrgovic, A.-M. (2020), "Spatial issues of sharing economy in polish accommodation market", Ekonomia i Srodowisko, No. 1, pp. 87-106.

Robertson, D., Oliver, C. and Nost, E. (2020), "Short-term rentals as digitally-mediated tourism gentrification: impacts on housing in New Orleans", Tourism Geographies. https://doi.org/10.1080/14616688.2020.1765011

Rubino, I., Coscia, C. and Curto, R. (2020), "Identifying Spatial Relationships between Built Heritage Resources and Short-Term Rentals before the Covid-19 Pandemic: Exploratory Perspectives on Sustainability Issues", Sustainability, Vol. 12, No. 11, 4533. https://doi.org/10.3390/su12114533

Rubino, I. and Coscia, C. (2019), "Airbnb revenue generation in the urban context: An analysis of renting patterns and dynamics", in Smart Innovation, Systems and Technologies, Springer Science and Business Media Deutschland GmbH, pp. 643-651.

Sainaghi, R. and Baggio, R. (2020), "Substitution threat between Airbnb and hotels: Myth or reality?", Annals of Tourism Research, Vol. 83, 102959. https://doi.org/10.1016/j.annals.2020.102959

Sales-Favà, J. and Módenes, J.A. (2017), "The Impact of Short-Time Rentals in the Demography of Touristic Neighborhoods: the case of Barcelona", in International Population Congress.

Sandusky, K., Soloveichik, R. and Spletzer, J. (2019), Peer-to-Peer Home Rentals in Government Statistics.

Sawatzky, K. (2016), Short-term Consequences: Investigating the Extent, Nature and Rental Housing Implications of Airbnb Listings in Vancouver by, Simon Fraser University.

Scassa, T. (2018), "Information Law in the Platform Economy: Ownership, Control, and Reuse of Platform Data", in McKee, D. et al. (Eds.), Law and the 'Sharing Economy', University of Ottawa Press, Ottawa, pp. 151-194.

Scassa, T. (2019), "Ownership and control over publicly accessible platform data", Online Information Review.

Schäfer, M. and Tran, K. (2020), Airbnb, Hotels, and Localized Competition, Berlin.

Somers, L., Dewit, I. and Baelus, C. (2018), "Understanding product-service systems in a sharing economy context - A literature review", Procedia CIRP, Vol. 73, pp. 173-178 https://doi.org/10.1016/j.procir.2018.03.317

Standing, C., Standing, S. and Biermann, S. (2019), "The implications of the sharing economy for transport", Transport Reviews, Vol 39, No. 2, pp. 226-242. https://doi.org/10.1080/01441647.2018.1450307

Suciu, A.M. (2018), "The Impact of Airbnb on Local Labour Markets in the Hotel Industry in Germany", SSRN Electronic Journal.

Tenezakis, E. (2019), 'Live like a local'. Short-term rentals and the housing market : evidence from Paris and London, Paris School of Economics.

Tong, B. and Gunter, U. (2020), "Hedonic pricing and the sharing economy: how profile characteristics affect Airbnb accommodation prices in Barcelona, Madrid, and Seville", Current Issues in Tourism. https://doi.org/10.1080/13683500.2020.1718619

Tuatagaloa, P. and Osborne, B. (2018), Airbnb and Housing in Auckland, Auckland.

Urquhart, C. (2012), Grounded theory for qualitative research: A practical guide, Sage, London.

Uzunca, B. and Borlenghi, A. (2019), "Regulation strictness and supply in the platform economy: the case of Airbnb and Couchsurfing", Industry and Innovation, Vol. 26, No. 8, pp. 920-942. https://doi.org/10.1080/13662716.2019.1633278 
ToSEE - Tourism in Southern and Eastern Europe, Vol. 6, pp. 573-585, 2021.

A. Pawlicz, C. Prentice: UNDERSTANDING SHORT-TERM RENTAL DATA SOURCES ...

Valdivielso, J. and Moranta, J. (2019), "The social construction of the tourism degrowth discourse in the Balearic Islands", Journal of Sustainable Tourism, Vol. 27, No. 12, pp. 1876-1892. https://doi.org/10.1080/09669582.2019.1660670

Wachsmuth, D. and Weisler, A. (2018), "Airbnb and the Rent Gap: Gentrification Through the Sharing Economy", Environment and Planning A: Economy and Space, Vol. 50, No. 6, pp. 1147-1170. https://doi.org/10.1177/0308518X18778038

Wegmann, J. and Jiao, J. (2017), "Taming Airbnb: Toward guiding principles for local regulation of urban vacation rentals based on empirical results from five US cities", Land Use Policy, Vol. 69, pp. 494501. https://doi.org/10.1016/j.landusepol.2017.09.025

Yrigoy, I. (2019), "Rent gap reloaded: Airbnb and the shift from residential to touristic rental housing in the Palma Old Quarter in Mallorca, Spain", Urban Studies, Vol. 56, No. 13, pp. 2709-2726. https://doi.org/10.1177/0042098018803261

Zhao, D. and Rahman, M.J. (2019), "Effects of Airbnb Hosts' Quality and Quantity Attributes on Reservation Performance: the Case of Hong Kong", Academy of Marketing Studies Journal, Vol. 23, No. 2, pp. $1-13$

Adam Pawlicz, PhD, Ass. Prof.

University of Szczecin, Poland,

Management Institute

Cukrowa 8, Szczecin, Poland

+48914443169

Adam.pawlicz@usz.edu.pl

Catherine Prentice, Ass. Prof

Griffith University, Australia

c.prentice@griffith.edu.au 